\title{
Surgical Clipping of a Basilar Tip Aneurysm: Case Report and Literature Review
}

\author{
Médard Kakou, Alban Slim Mbende, Fulbert Kouakou, Phanré Doua
}

Neurosurgery Unit, Yopougon Teaching Hospital, Abidjan, Ivory Coast

Email:mdkakou@yahoo.fr

How to cite this paper: Kakou, M., Mbende, A.S., Kouakou, F. and Doua, P. (2017) Surgical Clipping of a Basilar Tip Aneurysm: Case Report and Literature Review. Open Journal of Modern Neurosurgery, 7, 55-64. https://doi.org/10.4236/ojmn.2017.73007

Received: May 11, 2017

Accepted: July 1, 2017

Published: July 4, 2017

Copyright $\odot 2017$ by authors and Scientific Research Publishing Inc. This work is licensed under the Creative Commons Attribution International License (CC BY 4.0).

http://creativecommons.org/licenses/by/4.0/ (c) (i) Open Access

\begin{abstract}
Basilar tip aneurysms account for $5 \%-8 \%$ of all intracranial aneurysms. They are known to rupture more frequently than aneurysms in other locations. Surgical clipping of basilar apex aneurysms however challenging; remains the treatment of choice in Ivory Coast due in part, to multiple technical barriers. A 60-year-old right-handed patient presented to our Neurosurgical Unit in February $2^{\text {nd }} 2013$ after a sudden onset of altered consciousness. Neurological examination revealed both an upper motor neuron and meningeal syndromes with a Glasgow Coma Scale of 12. Brain NECT scan and a subsequent brain $\mathrm{CT}$ angiography showed a subarachnoid haemorrhage and a $3.8 \mathrm{~mm}$ (height) $\times$ $5.2 \mathrm{~mm}$ (width) basilar tip aneurysm respectively. Surgical clipping of the aneurysm was indicated but due to multiple technical barriers, surgery was delayed and the patient underwent surgery after the critical vasospasm period. The patient developed a hospital acquired pneumonia after surgery and was successfully treated with antibiotics. Since her discharge, she has been asymptomatic. We sought to report this case of a basilar apex aneurysm successfully occluded with non-ferromagnetic SUGITA clips and to share our experience of clipping these lesions through the frontotemporal approach. The patient was informed that non identifying information from the case would be submitted for publication, and she provided consent.
\end{abstract}

\section{Keywords}

Basilar Artery, Basilar Tip Aneurysm, Surgical Clipping

\section{Introduction}

Basilar tip aneurysms account for 5\% - 8\% of all intracranial aneurysms and 50\% of vertebro-basilar system aneurysms are located in the basilar apex [1] [2]. They carry a higher risk of rupture than aneurysms in other locations and constitute a major surgical challenge, due mainly to difficulties controlling proximal feeding 
arteries or complex anatomy of the basilar bifurcation and their depth within an extremely narrow surgical field [3] [4] [5]. General principles governing surgical treatment of intracranial aneurysms namely proximal and distal control of feeding arteries, microdissection, meticulous saving of thalamoperforating arteries and minimal injury to complex nerve structures are difficult to achieve in the setting of posterior circulation aneurysms [6]. But endovascular treatment of these aneurysms with complex techniques, such as double balloon remodelling, Y-stent-assisted coil embolization and Waffle-cone stenting is safe; but the extent medical literature is crowded with evidence of studies showing such techniques to be associated with relatively low complete occlusion rates and high recurrences and retreatment rates [7] [8]. Despite an ever-growing number of endovascular procedures being performed, giant or wide-necked aneurysms and those which involve the posterior cerebral artery at its neck generally are not occluded with endovascular techniques but are rather clipped [9]. In Ivory Coast, any endovascular technique is not yet available. Approaches to basilar bifurcation aneurysms in most series are the subtemporal, pterional, "half-and-half" and frontotemporal routes [10]-[15]. It is widely reported that each of these approaches have advantages and disadvantages and; they are nonetheless associated with some degree of morbidity and mortality [3] [16] [17] [18] [19]. We sought to report this case of a basilar apex aneurysm successfully occluded with non-ferromagnetic SUGITA clips and to share our experience of clipping these lesions through the frontotemporal approach. In the following, we will detail our clinical case and technical nuances of our surgical approach, as well as present our clinical experience with it.

\section{Case Report}

Mrs. OG, a 60-year-old right-handed patient presented to our Neurosurgical Unit in February $2^{\text {nd }} 2013$ after a sudden onset of altered consciousness. Her husband recalled Mrs. OG complaining of severe headaches which were associated with easy and projected vomiting before collapsing on the bed. She has not had any episode of fever nor convulsions prior to her admission. The patient has a 4-year history of a poorly treated high blood pressure and, sustained a left capsular-thalamic ischemic stroke 2 years before admission. The husband denied alcohol or tobacco use and pill medication. She is nonetheless diabetic and has reached menopause with no hormonal replacement treatment.

We examined Mrs. OG on arrival and found a patient with an altered consciousness, a Glasgow coma scale of 12; pupils were equal, normal size and reactive to light. The neck was stiff with positive Kerning and Brundzinski signs, a right hemiparesis (probably a sequelae of a previous stroke) with hyperactive reflexes and a Babinski sign on the right.

Brain NECT scan $24 \mathrm{~h}$ post ictus showed a subarachnoid haemorrhage around the basal cisterns, maximal in interpeduncular and prepontine cisterns (Figure 1(a) and Figure 1(b)). According to the WFNS and Fisher grading systems, the patient was grade IV on both scales. 
Brain CT angiography revealed a basilar tip aneurysm (Figure 2(a) and Figure 2(b)) which presented with a height of $3.8 \mathrm{~mm}$ and a lateral diameter of 5.2 $\mathrm{mm}$, and was oriented backward and $15 \mathrm{~mm}$ above the level of the dorsum sellae, on the right of the interpeduncular cistern.

Surgical clipping of the aneurysm was indicated but to multiple technical barriers, surgery was delayed and the patient underwent surgery after the critical vasospasm period.

Thirty days later, a thorough neurological examination revealed motor aphasia, right hemiparesis and a Glasgow coma scale of 13.

Brain NECT scan (Figure 3) showed persistent hydrocephalus and a lacunar ischemia in the left internal capsule consistent with the right hemiparesis.

Surgical clipping and third ventriculostomy was indicated and the patient underwent surgery on March $10^{\text {th }} 2013$.
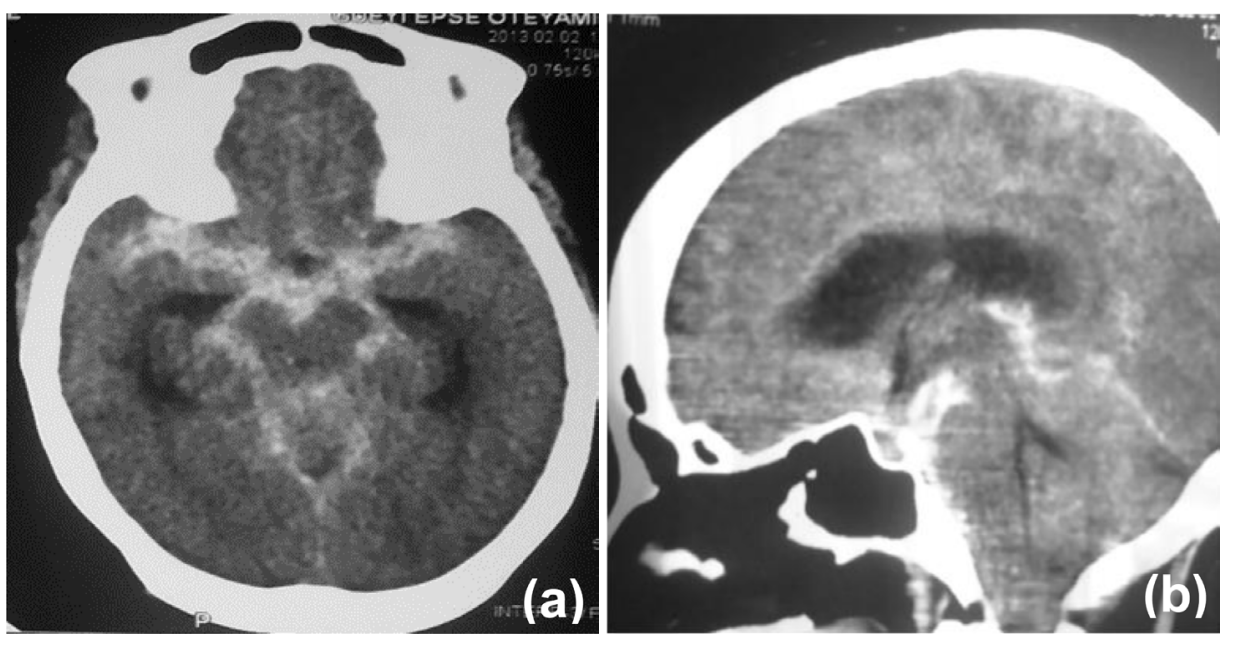

Figure 1. Brain NECT scan axial view (a) and sagittal view (b) showing subarachnoid haemorrhage around the basal cisterns, maximal in interpeduncular and prepontine cisterns.

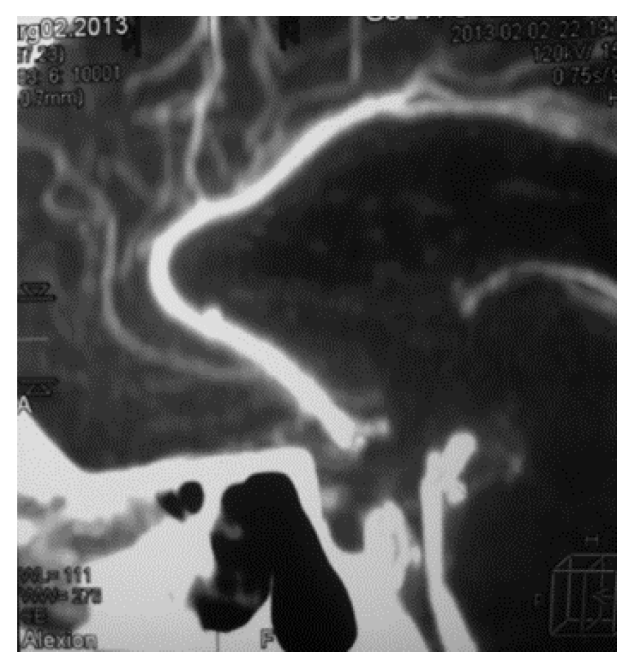

(a)



(b)

Figure 2. Brain CT angiography sagittal view (a) and coronal view (b) showing a basilar tip aneurysm oriented above the level of the dorsum sellae. 


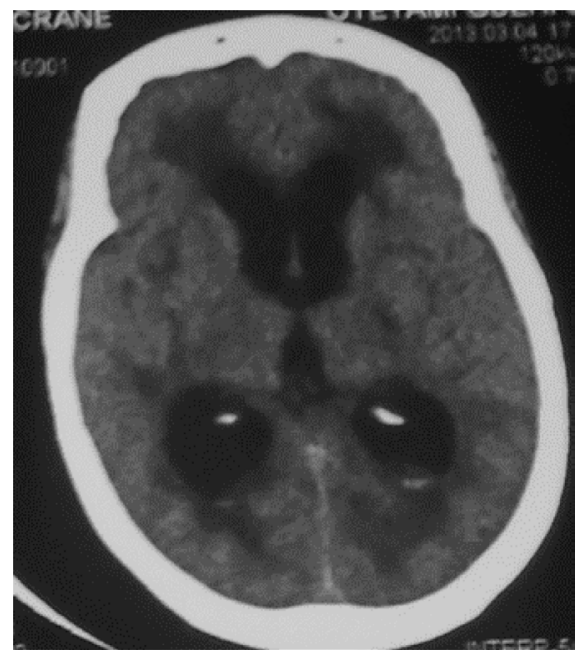

Figure 3. Brain NECT Scan axial view showing secondary hydrocephalus.

The patient was placed in the supine position with the head turned slightly $35^{\circ}$ to the left. A frontotemporal arch-shaped skin incision centered to the pterion was fashioned. It began immediately in front of the tragus and coursed slightly posterior, behind the hairline and superior to the highest point of the external ear; then curved medially and anteriorly to finish just behind the hairline in the frontal area. After retracting the skin flap anteriorly, careful interfascial dissection of the temporalis muscle was carried out to protect the frontal branch of the facial nerve. The temporalis muscle was retracted inferiorly, frontotemporal craniotomy was performed. After removing the bone flap, and beginning at the frontal limit of the craniotomy, an S-shaped dural incision was carried to the level of the impression of the lesser sphenoid wing. After opening the dura, we punctured the frontal horn of the right lateral ventricle to drain $15 \mathrm{ml}$ of CSF which relaxed the brain cortex. Then the sylvian fissure and basal cisterns were widely dissected (Figure 4). Further drainage of the chiasmatic cistern allowed maximal brain relaxing. Outer and inner layers of middle fossa dura were separated by blunt dissection and, such blunt dissection was continued medially until exposure of the anterior clinoid process. Then the anterior clinoid process, and the optic strut were removed, exposing the supraclinoid segment of the internal carotid artery until its bifurcation. Dura was incised medially toward the optic sheath and the distal dural ring was divided laterally, anteriorly, and posteriorly, making it possible to mobilize the internal carotid artery. Retracting the intradural segment of the ICA medially, prevented excision of the posterior communicating artery. We proceeded to the identification of the right anterior choroid and posterior communicating arteries, and the latest appeared small. Further dissection exposed the right oculomotor nerve and its vascular relationships as it courses between the posterior cerebral artery and the anterior and superior cerebellar artery. As we followed the right P2 and P1 segments of the posterior cerebral artery, the neck of the aneurysm was identified. After dissecting the neck, a right non-ferromagnetic SUGITA clip was inserted. To assure total exclusion 
of the aneurysm, a second clip was inserted just below the first clip (Figure 5(a) and Figure 5(b)); and that goal was achieved.

The second phase of the operation consisted in performing the third ventriculostomy through an opening of the lamina terminalis.

We completed our surgery by abundant rinsing with saline until satisfactory clearing of the working space. The dura was closed and suspended as was the bone flap. The skin was closed and two drains (one extradural and another subgaleal) were left in place.

The patient developed a hospital acquired pneumonia after surgery and was successfully treated with antibiotics. Following the antibiotics course, her clinical status improved significantly and was discharged 21 days after surgery with outpatient appointments for further follow-up. She was reviewed 3 and 6 months



Figure 4. Surgical exposure of the lateral fissure. The supraclinoid portion of the ICA bifurcates laterally at the optic chiasma into the anterior cerebral artery (A1) and middle cerebral artery (M1). ON optic nerve, FL frontal lobe, TL temporal lobe, III $3^{\text {rd }}$ cranial nerve and PCoA posterior communicating artery.
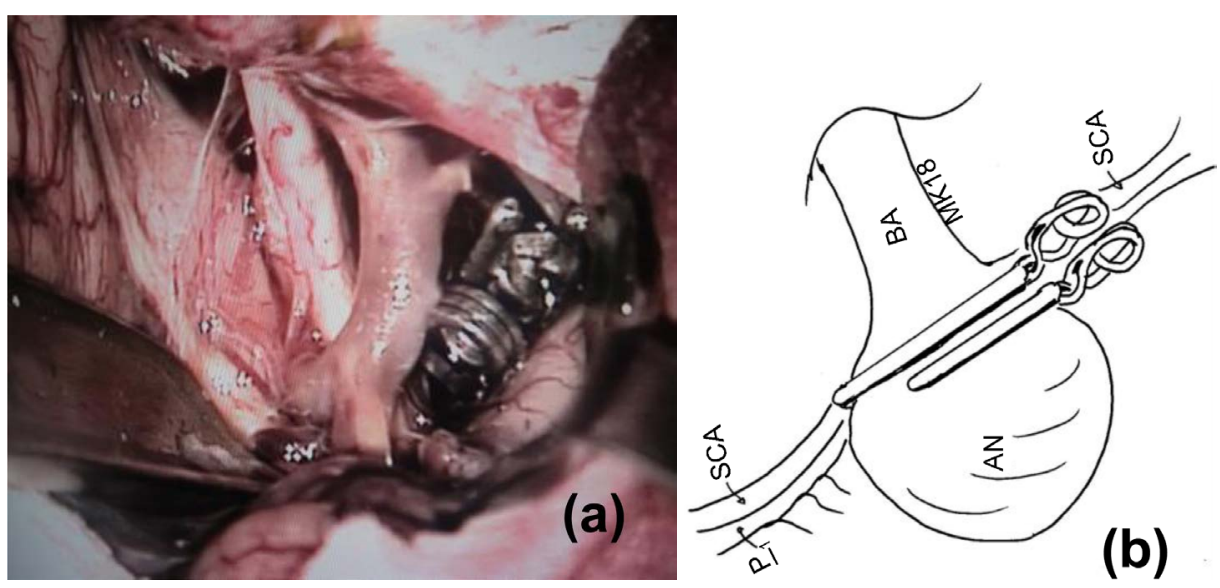

Figure 5. (a) (b): Clipping the basilar tip aneurysm neck. 
later and did not yield any clinical sign of relapse and since, she has been asymptomatic.

\section{Discussion}

Endovascular therapy has largely replaced microsurgical clipping for the treatment of basilar tip aneurysms since the dawn of the International Subarachnoid Aneurysm Trial, which associated in its findings with higher morbidity and mortality to surgical clipping of basilar bifurcation aneurysms [20]. In most modern centres, the majority of basilar apex aneurysms are treated via endovascular means, albeit with the expectation of relatively low complete occlusion rates and a higher percentage of recurrences and retreatment [21]. Microsurgery is still appropriate for aneurysms with complex neck morphologies and in young patients desiring a more durable treatment [22].

In most series, approaches to basilar bifurcation aneurysms are via the subtemporal, pterional, "half-and-half" and frontotemporal routes [10] [11] [12] [13] [15]. It is widely reported that each of these approaches have advantages and disadvantages and; they are nonetheless associated with some degree of morbidity and mortality [3] [16] [17] [18] [19]. Anatomical complexity of these lesions has led to the variations of these conventional techniques as attempts to overcome obvious limitations during surgery [9] [23]-[33]. Unfortunately, such variations have not provided adequate solutions to problems presented by limited working space at the depths of some basal cisterns.

Depending on the orientation of the basilar apex aneurysm, many authors usually associate the orbitozygomatic osteotomy with high basilar bifurcation aneurysms and the transcavernous-transsellar approach with low-lying lesions [16] [26] [33] [34]. Our patient's lesion was $15 \mathrm{~mm}$ above the level of the dorsum sellae, which is a high basilar tip aneurysm; and would have benefitted from a pterional approach with orbitozygomatic osteotomy. This approach is anatomically damaging however, and we held the view that the frontotemporal perspective would be less invasive or just well suited for the lesion; and we were confident that our choice would be vindicated by the outcome, which turned out to be the case. We performed a frontotemporal approach combined with an anterior clinoidectomy. Medial retraction of the ICA was helpful indeed, in a sense that routine resection of the posterior communicating artery, presented in most series, was not necessary in our case [1] [35]. In addition to the main lesion, the patient developed hydrocephalus and given the peculiar surgical trajectory of our approach; performing a third ventriculostomy became straightforward. It is the authors' personal experience that wider dissection of the sylvian fissure provided a sufficient access to the aneurysm neck and the interpeduncular fossa. The satisfactory view of the interpeduncular fossa through this trans-sylvian perspective, reduces subsequent traction on the temporal lobe and manipulation of the III cranial nerve [36]. The subsequent anterior clinoidectomy widened the working space, allowing sufficient mobilization of the internal carotid artery. Such action is helpful in successfully clipping aneurysms as high as that of our 
patient [37].

Yasargil is known to have initiated the frontotemporal approach as a standard approach for skull base surgery. The frontotemporal approach when combined with an anterior clinoidectomy is particularly useful for treating most basilar artery bifurcation aneurysms located between the clivus and a line $1 \mathrm{~cm}$ above the posterior clinoid processes.

Drake and Peerless devised this approach as a mean of treating posterior circulation aneurysms associated with anterior circulation ones and; the surgeon may choose the ideal trajectory and change the angle of view, depending on the peculiarities of each specific case [7] [16] [38]. However, changing the angle of view does not always provide additional space at the deep limits of the exposure [3] [4].

Opponents of the frontotemporal perspective have however, associated it with an approach with a reduced working space where the angle of view is narrow and oblique, especially for lesions hidden by posterior clinoid processes or the dorsum sellae and upper clivus [36] [39]. In the era of more advanced endovascular techniques, the bar for surgical expertise has been raised by selecting out groups of patients that have more difficult aneurysms [9]. More dramatic skull base approaches have been described to deal with such aneurysms, including anterior petrosectomy and the transcavernous approach [9] [24] [40] [41] [42]. These may be considered basal extensions of subtemporal and pterional approaches, respectively. But anterior petrosectomy provides a narrow working space and can cause serious damage to important neurovascular structures in the vicinity of the petrous bone. Dolenc described the transcavernous approach as a means of increasing the working space around the interpenducular and prepontine cisterns and provide a wider exposure of the deep anatomy [41]. This approach involves removing the anterior clinoid process, incising the distal and proximal dural rings, opening the cavernous sinus, and drilling the dorsum sellae and clivus to varying extents.

Sano described the temporopolar approach, also known as the half-and-half approach which provides a wider exposure of the interpeduncular fossa and sufficient proximal and distal control of the basilar and the posterior cerebral arteries respectively [23] [27] [36]. In a series reported by Sekhar et al., the authors used this perspective and performed an anterior petrosectomy to reduce bone constraints and achieved sufficient mobilization of the internal carotid artery [22].

\section{Conclusion}

Despite an ever-growing number of endovascular techniques, surgical clipping of basilar tip aneurysms remain the treatment of choice for giant or complex aneurysms and basilar artery bifurcation aneurysms of the youth. However complex and challenging the lateral sulcus approach may be, it is the authors' view that this approach is a valuable alternative to more traditional routes to basilar tip aneurysms. The frontotemporal approach when combined with anterior 
clinoidectomy is particularly useful for treating most basilar artery bifurcation aneurysms.

\section{Acknowledgements}

There is no conflict of interest from any of the authors.

\section{References}

[1] Le Roux, P.D. and Winn, H.R. (1998) Surgical Approaches to Basilar Bifurcation Aneurysms. Neurosurgery Clinics of North America, 9, 835-849.

[2] Drake, C.G., Peerless, S.J. and Hemesniemi, J. (1996) Surgery of Vertebrobasilar Aneurysms: London, Ontario; Experience on 1767 Patients. Springer-Verlag, New York, 300-311. https://doi.org/10.1007/978-3-7091-9409-6_25

[3] Figueiredo, E.G., Zabramski, J.M., Deshmukh, P., Crawford, N.R., Preul, M.C. and Spetzler, R.F. (2006) Anatomical and Quantitative Description of the Transcavernous Approach to Interpeduncular and Prepontine Cisterns. Journal of Neurosurgery, 104, 957-964. https://doi.org/10.3171/jns.2006.104.6.957

[4] Figueiredo, E.G., Zabramski, J.M., Deshmukh, P., Crawford, N.R., Spetzler, R.F. and Preul, M.C. (2006) Comparative Analysis of Anterior Petrosectomy and Transcavernous Approaches to Retrosellar and Upper Clival Basilar Artery Aneurysms. Neurosurgery, 58, 13-21.

[5] Lozier, A.P., Kim, G.H., Sciacca, R.R., Connolly Jr., E.S. and Solomon, R.A. (2004) Microsurgical Treatment of Basilar Apex Aneurysms: Perioperative and Long-Term Clinical Outcome. Neurosurgery, 54, 286-299. https://doi.org/10.1227/01.NEU.0000103222.13642.00

[6] Shi, X., Qian, H., Singh, K.C.K.I., Zhang, Y., Zhou, Z., Sun, Y. and Liu, F. (2013) Surgical Management of Vertebral and Basilar Artery Aneurysms: A Single Centre Experience in 41 Patients. Acta Neurochirurgica, 155, 1087-1093. https://doi.org/10.1007/s00701-013-1656-6

[7] Hernesniemi, J., Ishii, K., Niemela, M., Kivipelto, L., Fujiki, M. and Shen, H. (2005) Subtemporal Approach to Basilar Bifurcation Aneurysms: Advanced Technique and Clinical Experience. Acta Neurochirurgica, 94, 31-38. https://doi.org/10.1007/3-211-27911-3_6

[8] Higa, T., Ujiie, H., Kato, K., Kamiyama, H. and Hori, T. (2009) Basilar Artery Trunk Saccular Aneurysms: Morphological Characteristics and Management. Neurosurgical Review, 32, 181-191. https://doi.org/10.1007/s10143-008-0163-3

[9] Aziz, K.M.A., van Loveren, H.R., Tew Jr., J.M. and Chicoine, M.R. (1999) The Kawase Approach to Retrosellar and Upper Clival Basilar Aneurysms. Neurosurgery, 44, 1225-1236.

[10] Drake, C.G. (1961) Bleeding Aneurysms of the Basilar Artery. Journal of Neurosurgery, 18, 230-238. https://doi.org/10.3171/jns.1961.18.2.0230

[11] Behari, S., Das, K.R., Jaiswal, K.A. and Jain, K.V. (2009) Fronto-Temporo-Orbitozygomatic Craniotomy and "Half-and-Half" Approach for Basilar Apex Aneurysm. Neurology India, 57, 438-446. https://doi.org/10.4103/0028-3886.55609

[12] Drake, C. (1968) The Surgical Treatment of Aneurysms of the Basilar Artery. Journal of Neurosurgery, 29, 790-791.

[13] Yaşargil, M.G. (1984) Microneurosurgery: Clinical Considerations, Surgery of the Intracranial Aneurysms and Results. Vol. II, Thieme, Stuttgart.

[14] Hernesniemi, J. and Korja, M. (2014) At the Apex of Cerebrovascular Surgery- 
Basilar Tip Aneurysms. World Neurosurgery, 82, 37-39. https://doi.org/10.1016/j.wneu.2013.07.112

[15] Yaşargil, M.G., Antic, J., Laciga, R., Jain, K.K., Hodosh, R.M. and Smith, R.D. (1976) Microsurgical Pterional Approach to Aneurysms of the Basilar Bifurcation. Surgical Neurology, 6, 83-91.

[16] Ferreira, M.A.T., Tedeschi, H., Wen, H.T. and de Oliveira, E. (2000) Posterior Circulation Aneurysms: Guidelines to Management. Operative Techniques in Neurosurgery, 3, 169-178.

[17] Figueiredo, E.G., Gomes, M., Vellutini, E., Rosemberg, S. and Marino Jr., R. (2005) Angioleiomyoma of the Cavernous Sinus: Case Report. Neurosurgery, 56, E411. https://doi.org/10.1227/01.NEU.0000148003.42589.83

[18] Marlin, E.S., Ikeda, D.S., Shaw, A., Powers, C.J. and Sauvageau, E. (2014) Endovascular Treatment of Basilar Aneurysms. Neurosurgery Clinics of North America, 25, 485-494. https://doi.org/10.1016/j.nec.2014.04.007

[19] Samson, D.S., Hodosh, R.M. and Clark, W.K. (1978) Microsurgical Evaluation of Pterional Approach to Aneurysms of the Distal Basilar Circulation. Neurosurgery, 3, 135-141. https://doi.org/10.1227/00006123-197809000-00001

[20] Molyneux, A., Kerr, R., Stratton, I., Sandercock, P., Clarke, M., Shrimpton, J. and Holman, R. (2002) International Subarachnoid Aneurysm Trial Collaborative Group: International Subarachnoid Aneurysm Trial (ISAT) of Neurosurgical Clipping versus Endovascular Coiling in 2143 Patients with Ruptured Intracranial Aneurysms: A Randomised Trial. The Lancet, 360, 1267-1274.

https://doi.org/10.1016/S0140-6736(02)11314-6

[21] Colla, R., Cirillo, L., Princiotta, C., Dall'Olio, M., Menetti, F., Vallone, S. and Leonardi, M. (2013) Treatment of Wide-Neck Basilar Tip Aneurysms Using the Web II Device. The Neuroradiology Journal, 26, 669-677. https://doi.org/10.1177/197140091302600610

[22] Sekhar, L.N., Tariq, F., Morton, R.P., Ghodke, B., Hallam, D.K., Barber, J. and Kim, L.J. (2013) Basilar Tip Aneurysm: A Microsurgical and Endovascular Contemporary Series of 100 Patients. Neurosurgery, 72, 284-299. https://doi.org/10.1227/NEU.0b013e3182797952

[23] Sano, K. (1980) Temporo-Polar Approach to Aneurysms of the Basilar Artery at and around the Distal Bifurcation: Technical Note. Neurological Research, 2, 361367. https://doi.org/10.1080/01616412.1980.11739588

[24] Chanda, A. and Nanda, A. (2002) Anatomical Study of the Orbitozygomatic Transsellar-Transcavernous-Transclinoidal Approach to the Basilar Artery. Journal of Neurosurgery, 97, 151-160. https://doi.org/10.3171/jns.2002.97.1.0151

[25] Hakuba, A., Liu, S. and Nishimura, S. (1986) The Orbitozygomatic Infratemporal Approach: A New Surgical Technique. Surgical Neurology, 26, 271-276.

[26] de Oliveira E., Siqueira, M., Tedeschi, H. and Peace, D.A. (1993) Surgical Approaches for Aneurysms of the Basilar Artery Bifurcation. In: Matushima, T., Ed., Surgical Anatomy for Microsurgery VI. Cerebral Aneurysms and Skull Base Lesions, Sci Med Publications, Fukuoka City, 34-42.

[27] Heros, R. and Lee, S. (1993) The Combined Pterional/Anterior Temporal Approach for Aneurysms of the Upper Basilar Complex: Technical Report. Neurosurgery, 33, 244-251. https://doi.org/10.1227/00006123-199308000-00010

[28] Veznedaroglu, E., Benitez, R.P. and Rosenwasser, R.H. (2004) Surgically Treated Aneurysms Previously Coiled: Lessons Learned. Neurosurgery, 54, 300-305.

https://doi.org/10.1227/01.NEU.0000103223.90054.C2 
[29] Sugita, K., Kobayashi, S., Takemae, T., Tada, T. and Tanaka, Y. (1987) Aneurysms of the Basilar Artery Trunk. Journal of Neurosurgery, 66, 500-505. https://doi.org/10.3171/jns.1987.66.4.0500

[30] Day, J.D., Giannotta, S.L. and Fukushima, T. (1994) Extradural Temporopolar Approach to Lesions of the Upper Basilar Artery and Infrachiasmatic Region. Journal of Neurosurgery, 81, 230-235. https://doi.org/10.3171/jns.1994.81.2.0230

[31] Sato, S., Sato, M., Oizumi, T., Nishizawa, M., Ishizawa, M., Inamasu, G. and Kawase, T. (2001) Removal of Anterior Clinoid Process for Basilar Tip Aneurysm: Clinical and Cadaveric Analysis. Neurological Research, 23, 298-303. https://doi.org/10.1179/016164101101198523

[32] Matsuyama, T., Shimomura, T., Okumura, Y. and Sakaki, T. (1997) Mobilization of the Internal Carotid Artery for Basilar Artery Aneurysms Surgery. Technical Note. Journal of Neurosurgery, 86, 294-296. https://doi.org/10.3171/jns.1997.86.2.0294

[33] de Oliveira E., Tedeschi, E., Siqueira, M. and Peace, D.A. (1995) The Pretemporal Approach to the Interpeduncular and Petroclival Regions. Acta Neurochirurgica (Wien), 136, 204-211. https://doi.org/10.1007/BF01410627

[34] Nanda, A., Sonig, A., Banerjee, A.D. and Javalkar, V.K. (2014) Microsurgery Management of Basilar Artery Apex Aneurysms: A Single Surgeon's Experience from Louisiana State University, Shreveport. World Neurosurgery, 82, 118-129. https://doi.org/10.1016/j.wneu.2013.06.016

[35] Yasargil, M.G., Antic, J., Laciga, R., Jain, K.K., Hodosh, R.M. and Smith, R.D. (1976) Microsurgical Pterional Approach to Aneurysm of the Basilar Bifurcation. Surgical Neurology, 6, 83-91.

[36] Aziz, K.M.A., Andaluz, N. and Zuccarello, M. (2007) Basilar Bifurcation Aneurysm: Strategies for Surgical Approach Selection. Neurosurgery, 17, 101-112.

[37] Yonekawa, Y., Khan, N., Imhof, H.-G. and Roth, P. (2005) Basilar Bifurcation Aneurysm. Lesson Learnt from 40 Consecutive Case. Acta Neurochirurgica Supplements, 94, 39-44. https://doi.org/10.1007/3-211-27911-3_7

[38] Gonzalez, L.F., Amin-Hanjani, S., Bambakidis, N.C. and Spetzler, R.F. (2005) Skull Base Approaches to the Basilar Artery. Neurosurgical Focus, 19, 1-12. https://doi.org/10.3171/foc.2005.19.2.4

[39] Kakino, S., Ogasawara, Y., Nishimoto, H. and Ogawa, A. (2008) Subtemporal Approach to Basilar Tip Aneurysm with Division of the Posterior Communicating Artery: Technical Note. Vascular Health and Risk Management, 4, 931-935. https://doi.org/10.2147/VHRM.S2436

[40] Nutik, S.L. (1998) Pterional Craniotomy via a Transcavernous Approach for the Treatment of low-Lying Distal Basilar Aneurysms. Journal of Neurosurgery, 89, 921-926. https://doi.org/10.3171/jns.1998.89.6.0921

[41] Dolenc, V.V., Skrap, M., Sustersic, J., Skrbec, M. and Morina, A. (1987) A Transcavernous-Transellar Approach to the Basilar Tip Aneurysms. British Journal of Neurosurgery, 1, 251-259. https://doi.org/10.3109/02688698709035309

[42] Seoane, E., Tedeschi, E., de Oliveira, E., Wen, H.T. and Rhoton Jr., A.L. (2000) The Pretemporal Transcavernous Approach to the Interpeduncular and Prepontine Cisterns: Microsurgical Anatomy and Technique Application. Neurosurgery, 46, 891899. 
Submit or recommend next manuscript to SCIRP and we will provide best service for you:

Accepting pre-submission inquiries through Email, Facebook, LinkedIn, Twitter, etc. A wide selection of journals (inclusive of 9 subjects, more than 200 journals)

Providing 24-hour high-quality service

User-friendly online submission system

Fair and swift peer-review system

Efficient typesetting and proofreading procedure

Display of the result of downloads and visits, as well as the number of cited articles Maximum dissemination of your research work

Submit your manuscript at: http://papersubmission.scirp.org/

Or contact ojmn@scirp.org 